\title{
Therapy of acromegalic patients exacerbated by concomitant type 2 diabetes requires higher pegvisomant doses to normalise IGF1 levels
}

\author{
Michael Droste, Julia Domberg, Michael Buchfelder', Klaus Mann², \\ Anja Schwanke ${ }^{3}$, Günter Stalla ${ }^{4}$ and Christian J Strasburger ${ }^{5}$
}

Practice for Endocrinology and Diabetes, Elisenstraße 12, 26122 Oldenburg, Germany, ${ }^{1}$ Department of Neurosurgery, University of Erlangen-Nürnberg, Erlangen, Germany, ${ }^{2}$ Department of Endocrinology, University of Duisburg-Essen, Essen, Germany, ${ }^{3}$ Endocrine Care, Pfizer Pharma GmbH, Berlin, Germany, ${ }^{4}$ Department of Endocrinology, Max-Planck Institute of Psychiatry, Munich, Germany and ${ }^{5}$ Department of Medicine for Endocrinology, Diabetes and Nutritional Medicine, Charité Universitätsmedizin Berlin, Berlin, Germany
Correspondence should be addressed to M Droste Email droste@endokrin-ol.de

\begin{abstract}
Objective: Acromegaly is associated with an increased prevalence of glucose metabolism disorders. Clinically confirmed diabetes mellitus is observed in approximately one quarter of all patients with acromegaly and is known to have a worse prognosis in these patients.

Design: Of 514 acromegalic patients treated with pegvisomant and recorded in the German Cohort of ACROSTUDY, 147 had concomitant diabetes mellitus. We analysed these patients in an observational study and compared patients with and without concomitant diabetes.

Results: Under treatment with pegvisomant, patients with diabetes mellitus rarely achieved normalisation (64\% in the diabetic cohort vs $75 \%$ in the non-diabetic cohort, $P=0.04$ ) for IGF1. Diabetic patients normalised for IGF1 required higher pegvisomant doses (18.9 vs $15.5 \mathrm{mg}$ pegvisomant/day, $P<0.01$ ). Furthermore, those diabetic patients requiring insulin therapy showed a tendency towards requiring even higher pegvisomant doses to normalise IGF1 values than diabetic patients receiving only oral treatment ( $22.8 \mathrm{vs} 17.2 \mathrm{mg}$ pegvisomant/day, $P=0.11$ ).

Conclusions: Hence, notable interdependences between the acromegaly, the glucose metabolism of predisposed patients and their treatment with pegvisomant were observed. Our data support recent findings suggesting that intra-portal insulin levels determine the $\mathrm{GH}$ receptor expression in the liver underlined by the fact that patients with concomitant diabetes mellitus, in particular those receiving insulin therapy, require higher pegvisomant doses to normalise IGF1. It is therefore important to analyse various therapy modalities to find out whether they influence the associated diabetes mellitus and/or whether the presence of diabetes mellitus influences the treatment results of an acromegaly therapy.
\end{abstract}

\section{Introduction}

Acromegaly is a rare disease generally caused by a growth hormone $(\mathrm{GH})$-producing pituitary adenoma, which constantly secretes $\mathrm{GH}$. Untreated or insufficiently treated acromegaly leads to increased mortality rates, mainly due to cardiovascular diseases and neoplasms (1). The aim of the treatment of acromegaly thus is normalisation of both (c) 2014 European Society of Endocrinology Printed in Great Britain
GH level and the insulin-like growth factor 1 (IGF1) levels, which then lead to normalisation of mortality rates $(2,3)$.

Interestingly, patients with acromegaly associated with type 2 diabetes do not display added but exponentially increased mortality rates (1). However, concurrent manifestation of acromegaly and diabetes mellitus does 
not represent a particularly high activity of acromegaly, but depends on the genetic predisposition of the affected patients $(4,5)$.

Patients with type 2 diabetes or patients with metabolic syndrome are characterised by a progressive insulin resistance resulting in increased plasma insulin levels. This in turn has been associated with an increased rate of cardiovascular mortality and increased incidence of carcinomas $(6,7)$. Moreover, the various treatment modalities for type 2 diabetes affect the plasma insulin levels to different degrees. In particular, exogenous administration of insulin increases the plasma insulin levels of patients under treatment. The transition to insulin therapy regime without oral anti-hyperglycaemic agents is usually the last step in the escalation of therapy. In patients with type 2 diabetes, insulin resistance in target tissues (liver, muscle and adipose tissue) is a prominent feature. Thus, patients with diabetes under insulin therapy show the highest insulin resistance and the highest insulin levels in the peripheral blood. Peripheral insulin concentrations do reflect those in the portal vein (8), even in patients under insulin therapy. In patients without diabetes, increasing peripheral insulin levels by exogenous insulin suppresses the hepatic glucose production but in diabetics under insulin therapy the hepatic glucose production cannot be inhibited by plasma insulin concentrations throughout the physiologic range. Thus, patients on insulin therapy exhibit the highest portal insulin levels (9).

In accordance with the guidelines for the treatment of patients with acromegaly (10), selective transsphenoidal pituitary surgery is the first-choice therapy. In case of insufficient therapeutic success of the neurosurgery, radiotherapy or medical therapy are taken into consideration. The mainstay of medical therapy are somatostatin analogues (SSA), which have been used for more than 20 years and have proven effective in $\sim 60 \%$ of patients with residual disease after surgery. In patients with persistent residual acromegaly activity despite these therapeutic interventions, application of the $\mathrm{GH}$ receptor antagonist pegvisomant is indicated as a monotherapy or in the form of combination therapy, e.g. with SSA $(11,12)$. Consequently, $\sim 10-20 \%$ of patients need a therapy with pegvisomant.

In Germany, $\sim 90 \%$ of all patients treated with pegvisomant were recorded in a post-marketing surveillance study, the German Pegvisomant Observational Study (GPOS), starting immediately after approval and marketing authorisation of pegvisomant. In 2007, GPOS was transferred to the international ACROSTUDY.
By analysing the German cohort of ACROSTUDY, we sought to investigate the interaction of medical therapies for both acromegaly and diabetes in the group of patients with concomitant diseases.

\section{Subjects and methods}

\section{Setting: the German cohort of ACROSTUDY}

ACROSTUDY is a prospective observational study with the aim to record the safety and efficiency of pegvisomant treatment in patients with acromegaly. In January 2004, a non-interventional study named GPOS was started immediately after the marketing authorisation of pegvisomant was obtained in Germany at the end of 2003. All patients who had been treated with pegvisomant before that date within the scope of clinical studies in Germany were retrospectively recorded since the beginning of their pegvisomant therapy and have since been prospectively observed within GPOS. An independent ethics committee of Charité Universitätsmedizin Berlin has reviewed the observational study and all patients gave their written informed consent. Data on efficiency (13), the effect on quality of life (14), hepatotoxicity (15), pituitary tumour volume under therapy (16) and cardiovascular alterations (17) have previously been published. After the establishment of the international non-interventional study, ACROSTUDY, all monitored data were transferred from GPOS to ACROSTUDY. Therefore, data referring to the German cohort of ACROSTUDY include data from patients enrolled in the original GPOS cohort. Further on we will refer to the data analysed for this study report as the German cohort of ACROSTUDY.

\section{Participants}

At the time of the 10th evaluation of the German Cohort of ACROSTUDY (database freeze at 15 August 2011), 514 patients had been recorded who received pegvisomant at least once (safety population). These patients had been treated at 97 centres (partly practices with only one patient, partly centres with more than 20 patients were included in the study). The average duration of therapy was 174 weeks. In total, 1709 patient years under therapy had been recorded. This represents more than $80 \%$ of all pegvisomant prescriptions in Germany. Thus, an unusually stringent coverage of pegvisomant-treated patients with acromegaly is included in the German Cohort of ACROSTUDY. Inclusion criteria were limited to pegvisomant treatment of patients and the treating physician's 
willingness to contribute the data to the ACROSTUDY database as well as informed consent of the patient. Acromegaly treatment was carried out according to the guidelines for treatment of acromegaly (10) under the responsibility of the respective physician in charge.

We compare 147 patients with diabetes and 367 patients without diabetes out of the 514 patients from the safety population. We analysed the treatment of 121 patients with diabetes and 288 without diabetes out of the 409 patients with at least one subsequent examination.

\section{Treatment with pegvisomant}

In accordance with the approval specifications of pegvisomant in Germany and in conformity with the guidelines for treatment of acromegaly (18), patients received treatment with pegvisomant in cases where alternative options for treatment - in the first place surgery and/or radiotherapy of the pituitary adenoma, in the second place medical treatment with SSA and/or dopamine agonists - did not adequately reduce the acromegaly disease activity or showed intolerable side effects. In accordance with primary approval of the drug, therapy was generally carried out as a monotherapy. Under the responsibility of the respective attending physician, this therapy could, however, also be carried out as a combination therapy with SSA and/or dopamine agonists. At the time of the 10th analysis of data (15 August 2011), 359 patients received pegvisomant monotherapy and 155 patients received pegvisomant in combination with a SSA. Reasons for opting for a combined therapy were ascertained in a survey amongst 117 of the 155 patients receiving combination therapy. The most frequently given reasons in favour of a combined therapy were a lack of normalisation of the IGF1 level under monotherapy, headache and the size of the tumour or proximity of the residual tumour to the optic chiasm.

\section{Acromegaly-related data}

The pattern for acquisition of data was initial recording at the time before first application of pegvisomant, then every 6 months during the next 2 years, and subsequently every 12 months under ongoing therapy with pegvisomant.

The data included information on the patient's disease history, the symptoms of acromegaly, information on concomitant diseases and their medication as well as data on the previous treatment of acromegaly. At pegvisomant therapy initiation, and during the respective subsequent examinations under therapy, the following information was recorded: metric data; the current individual medication with regard to acromegaly, including accompanying medication; a locally measured IGF1 level, interpreted as multiples of the age-related upper limit of the normal range referring to the locally applied laboratory method; tumour volume by means of locally initiated magnetic resonance imaging (MRI) or computed tomography (CT) findings; glucose metabolism liver transaminases; and any adverse events under therapy.

\section{Glucose metabolism}

Within the framework of this post-authorisation study, glucose metabolism was recorded for all patients, at the point of inclusion into the study and at the points of the prospective visits: first every 6 months, then beyond 2 years of treatment every 12 months. Assessment included questions about the presence of diabetes mellitus, glucose levels at the point of data recording and the result of an HbA1c value assessed and interpreted locally, as well as questions on co-medication at the point of the respective data recording.

Patients were grouped into the diabetes mellitus group if one of the following criteria was met at any time point during the observational period of the study: diabetes mellitus was recorded by the treating physician as a concomitant disease, HbA1c was higher than $6.9 \%$, and patients received anti-diabetic therapy as listed in concomitant medication. The group of patients with diabetes was divided in subgroups of patients treated with or without insulin (Table 1).

Glycaemic management in the associated diabetes was under the responsibility of the respective physician as individualised treatment within the context of the needs, preferences and tolerances of each patient depended on the disease stages. Thus, metformin therapy is the first step, a combination of metformin with any oral antihyperglycaemic agent without sulphonylureas is the second step, and/or combination with sulphonylureas is the third step, and a kind of insulin therapy regime without oral anti-hyperglycaemic agents is the last step of therapy. We analysed the modalities of diabetes therapy of all the 121 patients with diabetes and at least one FU. In 110 patients, the state of diabetes management was known (72 of them under a mono-therapy with pegvisomant (mono) and 38 under a combination therapy pegvisomant and SSA (comb)). Information about the development of glycaemic management from baseline to the first FU was known in 73 patients ( 46 mono and 27 comb). From baseline to the first FU, the concept of diabetes therapy 
Table 1 Clinical characteristics of patients: comparison between patients with diabetes mellitus and without associated diabetes mellitus at the 10th analysis of the German Cohort of ACROSTUDY.

\begin{tabular}{|c|c|}
\hline & $\begin{array}{l}\text { Patients with } \\
\text { diabetes }\end{array}$ \\
\hline Number & 147 \\
\hline Proportion of male patients (\%) & $66(44.9 \%)$ \\
\hline Age (years) & $56.6 \pm 12.2$ \\
\hline Size $(\mathrm{cm})$ & $171.8 \pm 11.1$ \\
\hline Weight (kg) & $93.4 \pm 18.5$ \\
\hline BMI & $31.63 \pm 5.25$ \\
\hline Non-smoker (\%) & 70.9 \\
\hline Hypertension (n (\%)) & $108(74.0 \%)$ \\
\hline Age at diagnosis (years) & $46.6 \pm 11.9$ \\
\hline GH-prod. adenoma (\%) & 100 \\
\hline IGF1 levels at baseline (ng/ml) & $487.7 \pm 281.6$ \\
\hline Previous SSA therapy (\%) & 72.1 \\
\hline Patients with at least one FU & 121 \\
\hline
\end{tabular}

\begin{tabular}{l}
\hline $\begin{array}{l}\text { Patients without } \\
\text { diabetes }\end{array}$ \\
\hline 367 \\
$202(55.0 \%)$ \\
$47.2 \pm 14.6$ \\
$175.4 \pm 12.9$ \\
$88.8 \pm 20.6$ \\
$28.64 \pm 4.83$ \\
64.8 \\
$156(44.1 \%)$ \\
$39.2 \pm 13.2$ \\
99.7 \\
$491.0 \pm 252.9$ \\
77.4 \\
288
\end{tabular}

\begin{tabular}{l}
\hline Total \\
\hline 514 \\
$268(52.1 \%)$ \\
$49.9 \pm 14.6$ \\
$174.3 \pm 12.5$ \\
$90.2 \pm 20.1$ \\
$29.51 \pm 5.13$ \\
66.6 \\
$264(52.8 \%)$ \\
$41.3 \pm 13.3$ \\
99.8 \\
$490.0 \pm 261.4$ \\
75.9 \\
409 \\
\hline
\end{tabular}

\begin{tabular}{c} 
P value \\
\hline- \\
$0.04^{\mathrm{a}}$ \\
$<0.01^{\mathrm{a}}$ \\
$<0.01^{\mathrm{a}}$ \\
$0.03^{\mathrm{a}}$ \\
$<0.01^{\mathrm{a}}$ \\
$0.26^{\mathrm{b}}$ \\
$<0.01^{\mathrm{b}}$ \\
$<0.01^{\mathrm{a}}$ \\
$1.00^{\mathrm{b}}$ \\
$0.95^{\mathrm{a}}$ \\
$0.21^{\mathrm{b}}$ \\
-
\end{tabular}

Fisher's exact test.

changed in only eight patients (seven mono and one comb). In three patients the physician reduced the intensity of diabetes management and in only five patients (four under a monotherapy with pergvisomant and one combination-therapy pergvisomant and SSA) the physician intensified the treatment of diabetes mellitus. Thus, changes in HbA1c values could not be explained by changing the concept of diabetes management.

\section{Laboratory analyses}

All laboratory analyses included in the study (IGF1 level, glucose level, HbA1c value) were carried out in the local laboratory of the treating physician and interpreted by the respective physician in charge, on the basis of reference values adapted to the age and gender of the patient.

Achievement of the therapy objective, i.e. decrease in the IGF1 value into the age-related reference range of the locally applied laboratory method, was determined and indicated by the respective attending physician.

\section{Statistical analysis}

Descriptive data from this observational study are presented as mean \pm s.D. unless otherwise noted. Exploratory tests were carried out using Fisher's exact test. Owing to the group size, the assumption of normally distributed data even for subgroup analyses, such as patients with diabetes on monotherapy $(n=57)$ vs combination therapy $(n=28)$, appeared justified. The $t$-test was used for between-group comparisons and significance was considered at a 0.05 level.

In the post-marketing surveillance, data were only partially documented. Missing data do not result from drop-outs but mostly from missing documentation at baseline. Thus, we made a sensitivity analysis to assess the impact of the missing data. Incomplete data were available mainly for the HbA1c values during baseline to the first FU (only HbA1c values at baseline and FU in 85 out of 121 patients with diabetes, Table 2). In the sensitivity analysis, the missing data were replaced by s.E.M.

Table 2 Changes in the HbA1c value and the IGF1 levels within 6 months only for $n=121$ patients with diabetes and data from at least one follow-up. A sensitivity analysis to assess the impact of the missing $\mathrm{HbA1c}$ values showed no other findings.

\begin{tabular}{|c|c|c|c|}
\hline & Total & Monotherapy & Combined therapy \\
\hline Average value of $\mathrm{HbA} 1 \mathrm{c}$ at the beginning of therapy (\%) & $7.0 \pm 1.3$ & $7.1 \pm 1.4$ & $6.7 \pm 1.0$ \\
\hline Average change in $\mathrm{HbA} 1 \mathrm{c}$ from baseline to 6 months (\%) & $-0.394(n=85)$ & $-0.498(n=57)$ & $-0.181(n=28)$ \\
\hline Significance & $<0.01$ & $<0.01$ & 0.26 \\
\hline Average value of IGF1 at the beginning of therapy $(\mathrm{ng} / \mathrm{ml})$ & $501.0 \pm 278.5$ & $495.7 \pm 276.2$ & $513.3 \pm 287.2$ \\
\hline Average decrease in IGF1 from baseline to 6 months $(\mathrm{ng} / \mathrm{ml})$ & $-191.4(n=115)$ & $-193.7(n=81)$ & $-185.8(n=34)$ \\
\hline Significance & $<0.01$ & $<0.01$ & $<0.01$ \\
\hline
\end{tabular}


Calculated in this way, the means and $P$ values changed were irrelevant, resulting in no changes in the significances.

\section{Results}

\section{Clinical characteristics of patients}

Data on glucose metabolism were collected under the aspect of safety. Subsequently, the total cohort was divided in two parts: patients with diabetes and without diabetes. The clinical characteristics of these patients are shown in Table 1. Patients with diabetes were on average 10 years older than patients without diabetes $(P<0.01)$ and their acromegaly was diagnosed at a later age $(P<0.01)$. The other parameters of the metabolic syndrome, such as body weight, described as BMI $(P<0.011)$, and hypertension $(P<0.01)$ were more frequent in patients with diabetes.

For both groups of patients - diabetic and nondiabetic - data on acromegaly disease characteristics did not differ. The disease was caused by a GH-producing adenoma (99.8\%). The IGF1 levels were similar $(P=0.95)$, even if the IGF1 levels were not age corrected, and patients with diabetes had no higher incidence of a previous treatment with an SSA (72.1 vs $77.4 \%, P=0.21)$.

\section{Effect of the acromegaly treatment on glucose metabolism}

Assessing the effect of the acromegaly treatment on glucose metabolism over the course of the study was based on a change in the HbA1c value, which has been observed from the time point of inclusion (baseline, time point zero) to the first subsequent examination (i.e. 6 months after initiation of pegvisomant therapy). Thus, the immediate effect of the acromegaly treatment on glucose metabolism could be evaluated.

Table 2 reveals the changes regarding the metabolic condition documented for 85 of the 121 diabetic patients with at least one subsequent examination at therapy initiation by means of the HbA1c value. For the remaining 36 patients (30\%) as to the observational nature of the study, either baseline- or follow-up data were missing. The analysis reveals a significant decrease in the HbA1c value, showing a positive effect on the glucose metabolism $(P<0.01)$ for the documented 85 patients. However, this positive change mainly applied to patients under pegvisomant monotherapy. Despite the highly significant reduction in IGF1 levels with either pegvisomant monotherapy or SSA combination therapy, amounting to -193 and $-185 \mathrm{ng} / \mathrm{ml}$, respectively, the decrease in mean HbA1c levels during the first 6 months (of therapy) was only significant for patients on pegvisomant monotherapy alone $(P<0.01)$, whereas for patients receiving combination therapy HbA1c values were not significantly reduced $(P=0.26)$ (Table 2 and Fig. 1$)$.

\section{Influence of diabetes mellitus on treatability of acromegaly}

For the 409 patients with at least one subsequent examination beyond baseline, further information, whether these patients were with or without diabetes mellitus at pegvisomant initiation, was available.

Table 3 shows the proportion of patients who achieved the therapy objective, as well as the time required to normalise IGF1 levels, split into a diabetic and a nondiabetic patients group.

Diabetic patients $(n=121)$ achieved IGF1 normalisation to a smaller extent than patients without diabetes (64 vs $75 \%, P=0.04$ ). No difference regarding the duration until normalisation was seen $(P=0.04)$. However, the pegvisomant dose required for normalisation was significantly higher for diabetic patients $(P<0.01)$ (Table 3$)$.

For all 121 diabetic patients (with at least one documented follow-up visit), data regarding insulin treatment were available. In order to gain insights into which therapy modalities for diabetes mellitus have an effect on treatability of acromegaly, the diabetic patients group was subdivided into patients with insulin therapy and patients without insulin treatment (Table 4).

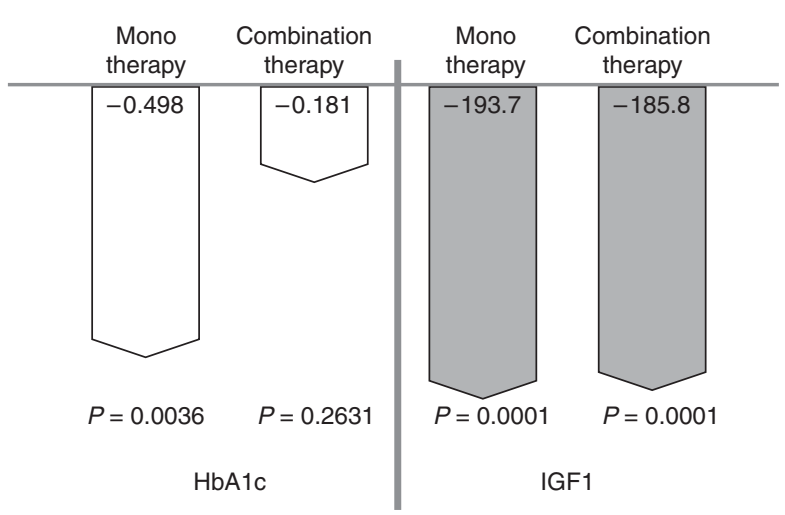

\section{Figure 1}

Changes in the HbA1c value and in IGF1 levels during the initial 6 months of pegvisomant treatment. 
Table 3 Baseline characteristics of all patients included in the German Cohort of ACROSTUDY, with at least one subsequent examination. The analysis of covariance (ANCOVA) with age, $B M I$, sex and diabetes mellitus at baseline shows a significant influence of BMI, age and sex, but the influence of presence of diabetes on the required pegvisomant doses was unchanged and still significant $(P<0.01)$.

\begin{tabular}{|c|c|c|c|}
\hline & $\begin{array}{l}\text { Patients } \\
\text { with } \\
\text { diabetes }\end{array}$ & $\begin{array}{l}\text { Patients } \\
\text { without } \\
\text { diabetes }\end{array}$ & $P$ value \\
\hline Number of patients $(n)$ & 121 & 288 & \\
\hline $\begin{array}{l}\text { Proportion of patients } \\
\text { achieving IGF1 } \\
\text { normalisation (\%) }\end{array}$ & $78(64 \%)$ & $216(75 \%)$ & $0.04^{a}$ \\
\hline $\begin{array}{l}\text { Time to IGF1 } \\
\text { normalisation (month) }\end{array}$ & 11.19 & 12.25 & $0.42^{b}$ \\
\hline $\begin{array}{l}\text { Pegvisomant dose at } \\
\text { normalisation (mg/day) }\end{array}$ & 18.87 & 15.50 & $<0.01^{b}$ \\
\hline
\end{tabular}

No differences were seen between diabetics with insulin treatment and diabetics without insulin treatment regarding IGF1 normalisation and time required until normalisation. However, the pegvisomant dose used at the time point of IGF1 normalisation in diabetic patients receiving exogenous insulin showed a non-significant tendency to be higher than in diabetic patients with oral treatment $(P=0.11)$.

Diabetic patients in general - especially those on insulin therapy - required significantly higher pegvisomant doses to normalise IGF1 levels compared with nondiabetic patients. These findings strongly indicate that higher pegvisomant doses are needed to guarantee an adequate disease control in diabetic patients (Fig. 2).

\section{Discussion}

The objective of the present evaluation of data, recorded in the German cohort of ACROSTUDY, was to examine key aspects to optimise acromegaly treatment given to patients who are affected by diabetes mellitus as a co-morbidity. Complex interactions between glucose metabolism, diabetes mellitus, insulin resistance, GH effects and acromegaly were seen. Considering these interactions with regard to acromegalic and diabetic treatment outcome is key.

GH directly influences glucose metabolism. Elevated GH levels are known to lead to increased insulin and glucagon concentrations although fasting glucose and oral glucose tolerance remain normal, indicating diminished insulin sensitivity (19). Rather depending on the genetic predisposition of individual patients than on the manifestation of acromegaly, insulin resistance leads to alterations in glucose metabolism, e.g. to a pathological glucose tolerance or manifest diabetes $(4,5)$. Patients without the risk of developing diabetes mellitus obviously can compensate the diminished insulin sensitivity caused by elevated GH levels - through increased insulin secretion.

A decrease in $\mathrm{GH}$, whether it is through discontinuation of a GH substitution in GH-deficient patients (20) or through a normalisation of elevated GH levels after an effective adenomectomy (21), leads to a rapid normalisation of insulin resistance.

Therefore, any successful therapy of acromegaly can be expected to positively influence insulin sensitivity and thereby possibly improve the metabolic status. This has been convincingly demonstrated for pituitary surgery $(22,23)$. With radiation therapy, these effects evolve much slower and are - based on their complexity - currently not described in the literature. Following radiation therapy, pituitary functions may vary individually or hypothalamic regulations may arise in addition to reduced GH levels. Both of these could influence insulin sensitivity.

How medical therapy with SSA, such as octreotide or lanreotide, or with the GH receptor antagonist (pegvisomant) influence the disease pattern of acromegalic patients has been described in various publications.

Table 4 Characterisation of all patients with diabetes mellitus included in the German Cohort of ACROSTUDY with at least one follow-up examination. The analysis of covariance (ANCOVA) with age, BMI sex and diabetes mellitus at baseline shows a significant influence of $\mathrm{BMI}$, age and sex but the influence of insulin doses on the required pegvisomant doses was unchanged.

\begin{tabular}{|c|c|c|c|}
\hline & $\begin{array}{l}\text { Insulin at } \\
\text { baseline }\end{array}$ & $\begin{array}{l}\text { No insulin } \\
\text { at baseline }\end{array}$ & $P$ value \\
\hline Number of patients $(n)$ & 39 & 82 & \\
\hline $\begin{array}{l}\text { Proportion of patients } \\
\text { achieving IGF1 } \\
\text { normalisation }(\%)\end{array}$ & $23(59 \%)$ & $55(67 \%)$ & $0.42^{a}$ \\
\hline $\begin{array}{l}\text { Time to IGF1 } \\
\text { normalisation (months) }\end{array}$ & 10.47 & 11.48 & $0.66^{b}$ \\
\hline $\begin{array}{l}\text { Pegvisomant dose at } \\
\text { normalisation (mg/day) }\end{array}$ & 22.83 & 17.22 & $0.11^{b}$ \\
\hline
\end{tabular}




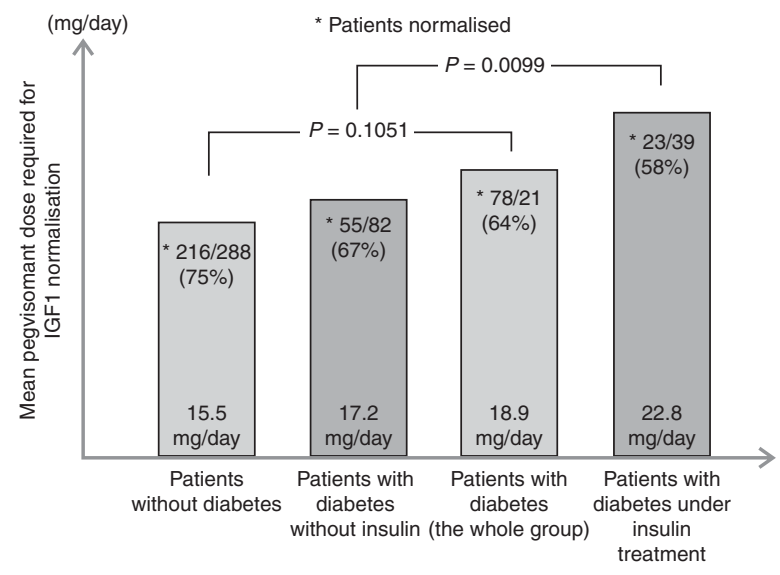

\section{Figure 2}

The pegvisomant dose required for normalisation of acromegaly disease activity, split by the presence of concomitant diabetes mellitus and its therapy.

Pegvisomant improves hepatic and peripheral insulin sensitivity, comparable with the effect of a successful pituitary surgery (24). In addition, pegvisomant influences both fasting and post-prandial insulin levels exclusively by diminishing or abolishing the effect of GH. Neither fasting blood glucose nor glucose tolerance changes under pegvisomant in healthy subjects (25). Moreover, no direct influence of pegvisomant on enterohepatic hormones such as insulin, glucagon, gastrin, pancreatic polypeptide or cholecystokinin was reported $(25,26)$.

There are data describing an increase in intraabdominal fat in patients with acromegaly successfully treated by pegvisomant (27). This could lead to a deterioration of insulin sensitivity. These observations, however, were made in patients with a regression in the IGF1 levels partly into the low normal range. Thus, this observation may be explained by a gradual over-treatment towards beginning hGH deficiency and does not reflect a hGH-independent effect of pegvisomant.

Decreased HbA1c levels show clinically significant effects of pegvisomant regarding the glucose metabolism of diabetic acromegaly patients. We were able to confirm our observation from a smaller cohort of patients demonstrating a significant regression in HbA1c levels observed in a larger group of diabetic patients with acromegaly. Furthermore, the mean decrease in the HbA1c typically depends on the respective baseline level, meaning higher HbA1c values at baseline tend to decrease to a greater extent. Marazuela et al. (28) reported a significant reduction in HbA1c values from $8.5 \pm 2.2$ to
$6.3 \pm 1.4 \%$ in 13 diabetics with acromegaly. Barkan et al. (29) also described a decrease from 7.8 (6.3-9.7) to 6.3 (5.9-6.8) \% among 13 diabetics. The mean HbA1c level in patients with diabetes mellitus in the German Cohort of ACROSTUDY $(n=85)$ at the initiation of pegvisomant therapy $(7.0 \pm 1.3 \%)$ was considerably lower. Accordingly, the improvement of metabolic status to an HbA1c value of $6.6 \pm 1.0 \%$ was less pronounced. After pegvisomant initiation, a potential need for intensified anti-diabetic treatment was not observed in any of the patients reported here.

It must, however, also be taken into consideration that not only pegvisomant treatment was initiated, but in the majority of patients also a previously implemented therapy with SSA had been discontinued at the same time.

Our data demonstrate for the first time that a positive influence of pegvisomant on the quality of diabetic metabolic status is only significant for patients under monotherapy. No significant improvement of diabetic metabolic status was verifiable in 22 diabetic patients with acromegaly under combination therapy with pegvisomant and SSA. It is well known that SSA causes an adverse effect on glucose metabolism. Cozzi et al. (30) described the recurrence of diabetes mellitus with an increase in $\mathrm{HbA1c}$ value over $6.0 \%$ among 20 patients of 110 (18\%) patients with acromegaly, under a long-acting octreotide treatment. The negative effect of SSA on carbohydrate metabolism could also be verified in healthy subjects. An increase in fasting blood glucose values and pronounced blood glucose up-regulation after oral glucose administration was shown (31), which underlines the existence of complex causal interactions of somatostatin with other enterohepatic hormones. In addition, an increase in fasting blood glucose, postprandial blood glucose including HbA1c values with simultaneous decrease in fasting and glucose-induced insulin levels (32), was described for acromegaly patients treated with octreotide or lanreotide. Under these conditions, the decrease in insulin levels does not reflect an improvement of insulin sensitivity, but is the result of a direct inhibition of $\beta$-cells by SSA. Physiologically, the enterohepatic hormone somatostatin inhibits the insulin secretion of $\beta$-cells mainly via the receptor subtype 5 (SSTR5). Further complex regulations, however, arise from somatostatin therapy such as inhibition of alpha cells, and thereby reduction in glucagon secretion (32), mainly via the receptor subtype 2 (SSTR2). The regulation of glucose homeostasis through the incretins, glucagon-like peptide 1 (GLP1) and glucosedependent insulinotropic polypeptide (GIP), is the result of a complex interaction of all three islet cell hormones, 
insulin, glucagon and somatostatin. Somatostatin is the essential mediator of insulin and glucagon secretion via SSTR2. The latter seems to be under a tonic control by somatostatin. Incretins seem to act within the endocrine pancreas via SSTR2 (33). The early, glucose-induced release of insulin primarily depends on this entero-insular axis. Depending on the dose, SSAs inhibit meal-dependent insulin secretion as well as GLP1 secretion. As a result, they also inhibit the protective effects of GLP1 and glucagon on adipogenesis and lipid metabolism (33).

The therapeutic use of SSA such as octreotide and lanreotide, which mainly act via an inhibition of SSTR2 and 5, does not lead solely to an inhibition of somatotrophic pituitary cells, but they ubiquitously stimulate the receptors and convey complex metabolic effects which are currently only clarified in part. This primarily shows detrimental effects on glucose metabolism if there is a genetic predisposition for metabolic diseases (34).

These interactions explain various data on glucose metabolism under SSA therapy in patients with acromegaly reported in the literature, depending on the examined patient group (4). The positive effect of an improvement of insulin resistance through decrease in $\mathrm{GH}$ is partially overplayed by the negative effect of an SSA therapy on $\beta$-cells and other enterohepatic hormones. It is not clear which consequences these complex regulations can have for the individual patients, depending on their individual predisposition.

Individual metabolic changes such as obesity, insulin resistance or diabetes mellitus must therefore be needed and taken into consideration during the medical therapy of acromegaly, not only with regard to changes in glucose metabolism through the acromegaly and its treatment, but also with regard to the treatability and the effects of acromegaly through an associated existing diabetes mellitus. Insulin plays the decisive role in this connection. High insulin levels have consequences on the effects of $\mathrm{GH}$

By analysing data from acromegaly patients treated with pegvisomant, we demonstrated that $\mathrm{GH}$ effects on hepatic IGF1 production are dependent on the extent of insulin levels. Diabetes mellitus type 2 is characterised by existence of peripheral and hepatic insulin resistance, i.e. elevated insulin levels. Exogenous insulin therapy will further increase insulin levels $(8,35,36)$. We demonstrated that patients with an associated diabetes had a significantly lower response to a pegvisomant therapy than patients without diabetes (65\% compared with $75 \%$ IGF1 normalisation rate). Our findings strongly confirm published observations (37) in which higher normalisation rates for IGF1 values among non-diabetic patients were found. That is probably due to the fact that patients with diabetes require significantly higher pegvisomant doses to achieve a sufficient therapeutic effect. The assumption that blood insulin levels determine the outcome of pegvisomant treatment is furthermore supported by the fact that the patients treated with exogenous insulin required the highest pegvisomant doses.

The modulation of biological GH actions and the effect of insulin on the biosynthesis and surface presentation of $\mathrm{GH}$ receptors on the hepatocyte and therefore the effect on hepatic IGF1 production have been experimentally documented (38), showing that insulin is essential for the effect of GH on hepatocytes. Moreover, insulinopaenic patients have lower GH-binding protein levels and show GH insensitivity.

Consequently, it may be expected that high insulin levels lead to a greater efficacy of GH on hepatocytes. Neggers et al. (39) summarised these observations in their hypothesis of an extra-hepatic acromegaly. SSA decreases not only the GH levels of the pituitary but also reduces the insulin production from the pancreatic $\beta$-cells. This may be resulting in normalised IGH1 GH levels but elevated extra-hepatic effect of GH under a monotherapy with SSA.

For the first time, we documented the clinical relevance of different hepatic insulin levels to the treatment of acromegaly in patients with concomitant diabetes mellitus. Published findings (40) in which pegvisomant doses required for an effective treatment depend on the patient's BMI support our results, in as much as the BMI is known to correlate with insulin levels.

\section{Conclusion}

The GH antagonist pegvisomant is one of the medical treatment options for acromegaly. Its use is indicated if other forms of therapy, surgery and/or radiotherapy and a medical therapy with dopamine agonists and/or SSA are not sufficiently effective.

The objective of treatment in acromegaly is not primarily the normalisation of $\mathrm{GH}$, but rather to normalise life expectancy and quality of life. This also depends on the individual characteristics of the affected patients. Patients with acromegaly and diabetes mellitus as co-morbidity - this probably also applies to patients with obesity as part of a metabolic syndrome - have a particularly high mortality rate and an impaired quality of life. The selection of a medical treatment strategy should therefore be made individually. 
The size of a residual tumour after surgery and the proximity to the optic chiasm are arguments favouring the application of SSA. However, tumour growth feared under pegvisomant is only observed in single individual cases, so that the existence of a residual tumour - especially if this has been irradiated - should not be the sole reason for the use of SSA (41).

The interaction of GH and insulin, the reciprocal influence with the effects on metabolic changes, and also the treatability of acromegaly, should be considered in the therapy planning. Patients with diabetes mellitus and patients with risk factors to develop diabetes benefit from pegvisomant as monotherapy. It should be considered whether pegvisomant could be first choice treatment option for such patients. It has to be noted that administration of pegvisomant in addition to an existing somatostatin therapy in this respect is not as successful as pegvisomant monotherapy.

\section{Declaration of interest}

M Droste, M Buchfelder, K Mann, G Stalla, and C J Strasburger are members of the Scientific ACROSTUDY German Board, which is sponsored by Pfizer $\mathrm{GmbH}$, Germany. C J Strasburger has received consultant fees as a member of ACROSTUDY Steering Committee. A Schwanke is currently employed by Pfizer GmbH Germany. K Mann is a member of the HNR board, which is funded by the Heinz Nixdorf Stiftung, Essen. M Buchfelder, K Mann, G Stalla and C J Strasburger received grants for other projects as well as lecture fees from Pfizer, Germany. J Domberg has nothing to declare.

Funding

ACROSTUDY is sponsored by Pfizer, Inc.

\section{Acknowledgements}

The authors gratefully acknowledge the excellent support and critical discussion of the ACROSTUDY board members. Moreover, the authors thank all the investigators and study nurses of the individual centres for contributing data to the ACROSTUDY.

\section{References}

1 Rajasoorya C, Holdaway IM, Wrigthson P, Scott DJ \& Ibbertson HK. Determinants of clinical outcome and survival in acromegaly. Clinical Endocrinology 199441 95-102. (doi:10.1111/j.1365-2265. 1994.tb03789.x)

2 Holdaway IM, Rajasoorya CR, Gamble GB \& Stewart AW. Long-term treatment outcome in acromegaly. Growth Hormone \& IGF Research 2003 13 185-192. (doi:10.1016/S1096-6374(03)00030-3)

3 Holdaway IM, Bolland MJ \& Gamble GD. A meta-analysis of the effect of lowering serum levels of GH and IGF-I on mortality in acromegaly. European Journal of Endocrinology 2008159 89-95. (doi:10.1530/EJE-08-0267)
4 Couture E, Bongard V, Maiza JC, Bennet A \& Caron P. Glucose status in patients with acromegaly receiving primary treatment with the somatostatin analog lanreotide. Pituitary 201215 518-525. (doi:10.1007/s11102-011-0361-9)

5 Kreze A, Kreze-Spirova1 E \& Mikulecky M. Risk factors for glucose intolerance in active acromegaly. Brazilian Journal of Medical and Biological Research 200134 1429-1433. (doi:10.1590/S0100879X2001001100009)

6 Hemminiki K, Li X \& Sundquist K. Risk of cancer following hospitalisation for type 2 diabetes. Oncologist 201015 548-555. (doi:10.1634/theoncologist.2009-0300)

7 Currie CJ, Poole CD \& Gale EA. The influence of glucose-lowering therapies on the cancer risk in type 2 diabetes. Diabetologia 200952 1766-1777. (doi:10.1007/s00125-009-1440-6)

8 Horowitz DL, Starr JI, Mako E, Blackard WG \& Rubenstein AH. Proinsulin, insulin and C-peptide concentrations in human portal an peripheral blood. Journal of Clinical Investigation 197555 1278-1283. (doi:10.1172/JCI108047)

9 Groop LC, Bonadonna RC, DelPatro S, Ratheiser K, Zyck K, Ferrannini E $\&$ DeFronzo RA. Glucose and free fatty acid metabolism in non-insulindependent diabetes mellitus. Journal of Clinical Investigation $1989 \mathbf{8 5}$ 205-213. (doi:10.1172/JCI114142)

10 Melmed S, Casanueva F, Cavagnini F, Chanson P, Frohman L, Grossman A, Ho K, Kleinberg D, Lamberts S, Laws E et al. Guidelines for acromegaly management: results of a multicenter trial. Journal of Clinical Endocrinology and Metabolism 200287 4054-4058. (doi:10.1210/ jc.2002-011841)

11 Neggers SJ, van Aken MO, Janssen JA, Feelders RA, de Herder WW \& van der Lely AJ. Long-term efficacy and safety of combined treatment of somatostatin analogs and pegvisomant in acromegaly. Journal of Clinical Endocrinology and Metabolism 200792 4598-4601. (doi:10.1210/ jc.2007-1234)

12 Trainer PJ, Drake WM, Katznelson L, Freda PU, Herman-Bonert V, van der Lely AJ, Dimaraki EV, Stewart PM, Friend KE, Vance ML et al. Treatment of acromegaly with the growth hormone receptor antagonist pegvisomant. New England Journal of Medicine 2000342 1171-1177. (doi:10.1056/NEJM200004203421604)

13 Schreiber I, Buchfelder M, Droste M, Forssmann K, Mann K, Saller B, Strasburger CJ \& German Pegvisomant Investigators. Treatment of acromegaly with the $\mathrm{GH}$ receptor antagonist pegvisomant in a clinical practice: safety and efficacy evaluation from the German Pegvisomant Observational Study. European Journal of Endocrinology 2007156 75-82. (doi:10.1530/eje.1.02312)

14 Sievers C, Brübach K, Saller B, Schneider HJ, Buchfelder M, Droste M, Mann K, Strasburger CJ \& Stalla GK. Change of symptoms and perceived health in acromegalic patients on pegvisomant therapy: a retrospective cohort study within the German Pegvisomant Observational Study (GPOS). Clinical Endocrinology 201073 89-94.

15 Biering H, Saller B, Bauditz J, Pirlich M, Rudolph B, Johne A, Buchfelder M, Mann K, Droste M, Schreiber I et al. Elevated transaminases during medical treatment of acromegaly: a review of the German pegvisomant surveillance experience and a report of a patient with histologically proven chronic mild active hepatitis. European Journal of Endocrinology 2006154 213-220. (doi:10.1530/eje.1.02079)

16 Buchfelder M, Weigel D, Droste M, Mann K, Saller B, Brübach K, Stalla GK, Bidlingmeier M \& Strasburger CJ. Pituitary tumor size in acromegaly during pegvisomant treatment: experience from MR re-evaluations of the German Pegvisomant Observational Study. European Journal of Endocrinology 2009161 27-35. (doi:10.1530/ EJE-08-0910)

17 Berg C, Petersenn S, Lahner H, Herrmann BL, Buchfelder M, Droste M, Stalla GK, Strasbvurger CJ, Roggenbuck U, Lehmann N et al. Cardiovascular risk factors in patients with uncontrolled an long-term acromegaly: comparison with matched data from the general population and the effect of disease control. Journal of Clinical Endocrinology and Metabolism 201095 3648-3656. (doi:10.1210/jc.2009-2570) 
18 SOMAVERT ${ }^{\circledR}$ SmPC, 2011. http://www.somavert.com/

19 Karlander S, Vranić M \& Efendić S. Increased glucose turnover and glucose cycling in acromegalic patients with normal glucose tolerance. Diabetologia 198629 778-783. (doi:10.1007/BF00873216)

20 Krusenstjerna-Hafstrøm T, Clasen BF, Møller N, Jessen N, Pedersen SB, Christiansen JS \& Jørgensen JO. Growth hormone (GH)-induced insulin resistance is rapidly reversible: an experimental study in GH-deficient adults. Journal of Clinical Endocrinology and Metabolism 201196 2548-2557. (doi:10.1210/jc.2011-0273)

21 Wasada T, Aoki K, Sato A, Katsumori K, Muto K, Tomonaga O, Yokoyama H, Iwasaki N, Babazono T, Takahashi C et al. Assessment of insulin resistance in acromegaly associated with diabetes mellitus before and after transsphenoidal adenomectomy. Endocrine Journal 199744 617-620. (doi:10.1507/endocrj.44.617)

22 Koshiyama H, Kawasaki Y, Iwasaki Y, Mori K, Honjo S, Hamamoto Y, Ikeda H, Nomura K, Wada Y, Takahashi Y et al. Correlation of serum IGF-I level with insulin resistance in patients with acromegaly. Endocrine Reviews 201132 P3-273. (doi:10.1210/er.2009-0043)

23 Møller N, Schmitz O, Jøorgensen JO, Astrup J, Bak JF, Christensen SE, Alberti KG \& Weeke J. Basal- and insulin-stimulated substrate metabolism in patients with active acromegaly before and after adenomectomy. Journal of Clinical Endocrinology and Metabolism 1992 74 1012-1019.

24 Lindberg-Larsen R, Møller N, Schmitz O, Nielsen S, Andersen M, Orskov H \& Jørgensen JO. The impact of pegvisomant treatment on substrate metabolism and insulin sensitivity in patients with acromegaly. Journal of Clinical Endocrinology and Metabolism 200792 1724-11728. (doi:10.1210/jc.2006-2276)

25 Parkinson C, Drake WM, Roberts ME, Meeran K, Besser GM \& Trainer PJ. A comparison of the effects of pegvisomant and octreotide on glucose, insulin, gastrin, cholecystokinin and pancreatic polypeptide responses to oral glucose and a standard mixed meal. Journal of Clinical Endocrinology and Metabolism 200287 1797-1804. (doi:10.1210/ jcem.87.4.8432)

26 Higham CE, Rowles S, Russell-Jones D, Umpleby AM \& Trainer PJ. Pegvisomant improves insulin sensitivity and reduces overnight free fatty acid concentrations in patients with acromegaly. Journal of Clinical Endocrinology and Metabolism 200987 2459-1463. (doi:10.1210/ jc.2008-2086)

27 Plöckinger U \& Reuter T. Pegvisomant increases intra-abdominal fat in patients with acromegaly: a pilot study. European Journal of Endocrinology 2008158 467-471. (doi:10.1530/EJE-07-0637)

28 Marazuela M, Lucas T, Alvarez-Escolá C, Puig-Domingo M, de la Torre NG, de Miguel-Novoa P, Duran-Hervada A, Manzanares R, Luque-Ramírez M, Halperin I et al. Long-term treatment of acromegalic patients resistant to somatostatin analogues with the GH receptor antagonist pegvisomant: its efficacy in relation to gender and previous radiotherapy. European Journal of Endocrinology 2009160 535-542. (doi:10.1530/EJE-08-0705)

29 Barkan AL, Burman P, Clemmons DR, Drake WM, Gagel RF, Harris PE, Trainer PJ, van der Lely AJ \& Vance ML. Glucose homeostasis and safety in patients with acromegaly converted from long-acting octreotide to pegvisomant. Journal of Clinical Endocrinology and Metabolism 200590 5684-5691. (doi:10.1210/jc.2005-0331)
30 Cozzi R, Attanasio R, Montini M, Pagani G, Lasio G, Lodrini S, Barausse M, Albizzi M, Dallabonzana D \& Pedroncelli AM. Four-year treatment with octreotide-long-acting repeatable in 110 acromegalic patients: predictive value of short-term results? Journal of Clinical Endocrinology and Metabolism 200388 3090-3098. (doi:10.1210/ jc.2003-030110)

31 Baldelli R, Battista C, Leonetti F, Ghiggi MR, Ribaudo MC, Paoloni A, D'Amico E, Ferretti E, Baratta R, Liuzzi A et al. Glucose homeostasis in acromegaly: effects of long-acting somatostatin analogues treatment. Clinical Endocrinology 200359 492-499. (doi:10.1046/j.1365-2265. 2003.01876.x)

32 Strowski MZ, Parmar RM, Blake AD \& Schaeffer JM. Somatostatin inhibits insulin and glucagon secretion via two receptors subtypes: an in vitro study of pancreatic islets from somatostatin receptor 2 knockout mice. Endocrinology 2000141 111-117.

33 De Heer J, Rasmnussen C, Coy DH \& Holst JJ. Glucagon-like peptide 1, but not glucose-dependent insulinotropic peptide, inhibits glucagon secretion via somatostatin (receptor subtype 2) in the perfused rat pancreas. Diabetologia 200851 2263-2270. (doi:10.1007/ s00125-008-1149-y)

34 Velasquez-Mieyer PA, Umpierrez GE, Lustig RH, Cashion AK, Cowan PA, Christensen M, Spencer KA \& Burghen GA. Race affects insulin and GLP-1 secretion and response to the long-acting somatostatin analogue in obese adults. International Journal of Obesity 200428 330-333.

35 Martin BC, Warram JH, Krolewski AS, Bergman RN, Soeldner JS \& Kahn CR. Role of glucose and insulin resistance in development of type 2 diabetes mellitus: results of a 25-year follow-up study. Lancet 1992 340 925-929. (doi:10.1016/0140-6736(92)92814-V)

36 Kahn CR. Banting Lecture: insulin action, diabetogenes, and the cause of type II diabetes. Diabetes 199443 1066-1084. (doi:10.2337/diab.43. 8.1066)

37 van der Lely AJ, Bernabeu I, Cap J, Caron P, Colao A, Marek J, Neggers S $\&$ Birman P. Coadministration of lanreotide Autogel and pegvisomant normalizes IGF1 levels and is well tolerated in patients with acromegaly partially controlled by somatostatin analogs alone. European Journal of Endocrinology 2011164 325-333. (doi:10.1530/EJE-10-0867)

38 Leung KC, Doyle N, Ballesteros M, Waters MJ \& HO KK. Insulin regulation of human growth hormone receptors: divergent effects on biosynthesis and surface translocation. Journal of Clinical Endocrinology and Metabolism $2000 \mathbf{8 5} 4712-4720$.

39 Neggers SJ, Kopchick JJ, Jorgensen JO \& van der Lely AJ. Hypothesis: extra-hapatic acromegaly: a new paradigm? European Journal of Endocrinology 2011164 11-16. (doi:10.1530/EJE-10-0969)

40 Parkinson C, Burman P, Messig M \& Trainer PJ. Gender, body weight, disease activity, and previous radiotherapy influence the response to pegvisomant. Journal of Clinical Endocrinology and Metabolism 200192 190-195. (doi:10.1210/jc.2006-1412)

41 Buhk JH, Jung S, Psychogios MN, Göricke S, Hartz S, Schulz-Heise S, Klingebiel R, Forsting M, Brückmann H, Dörfler A et al. Tumor volume of growth hormone-secreting pituitary adenomas during treatment with pegvisomant: a prospective multicenter study. Journal of Clinical Endocrinology and Metabolism 201095 552-558. (doi:10.1210/ jc.2009-1239)

Received 30 May 2013

Revised version received 5 March 2014

Accepted 15 April 2014 